\title{
Crystalline Structures of Poly (L-lactide) Formed under Pressure and Structure Transitions with Heating
}

Shaoyong Huang, ${ }^{\mathrm{a}}$ Hongfei Li*, ${ }^{\mathrm{b}}$ Donghong Yu, ${ }^{\mathrm{c}}$ Shichun Jiang ${ }^{*},{ }^{\mathrm{d}}$ Xuesi Chen*, Lijia An ${ }^{\text {b }}$

${ }^{\text {a }}$ Key Laboratory of Polymer Eco-materials Changchun Institute of Applied Chemistry, Chinese Academy of Sciences, Changchun 130022, P. R. China, b State Key Laboratory of Polymer Physics and Chemistry, Changchun Institute of Applied Chemistry, Chinese Academy of Sciences, Changchun 130022, P. R. China, c Department of Biotechnolgoy, Chemistry, and Environmental Engineering, Aalborg University, DK-9000, Aalborg, Denmark, ${ }^{\mathrm{d}}$ School of Materials Science and Engineering, Tianjin University, Tianjin 300072, P. R. China 
Abstract: The isothermally crystallized poly(L-lactide) (PLLA) samples were obtained at $135{ }^{\circ} \mathrm{C}$ under pressures $\left(\mathrm{P}_{\mathrm{c}}\right)$ ranging from 1 bar to $2.5 \mathrm{k}$ bar. The crystalline structures, the structure transition, and thermal properties of the prepared samples were investigated by wide-angle X-ray diffraction (WAXD), real time synchrotron small-angle X-ray scattering (SR-SAXS) and differential scanning calorimetry (DSC) during this process. The structural parameters, such as the size of crystallites, the inverse spacing, the long periods and lamellae thicknesses decrease with pressure increasing. Based on the peculiarities of crystalline structure and crystallization behaviors, low and high pressure regions were revealed: disordered $\alpha$ crystal was formed in the high pressure region $(>1 \mathrm{k}$ bar). A layer located intermediate between crystalline and melt-like regions was observed, which finally took on crystalline order. Reformation, disorder to order transformation, and recrystallization during heating completely changed the previous crystalline and stacking structure, a more stable crystalline structure was newly formed. The melting behaviors of samples indicate the crystalline and stacking structure formed under high pressure are more stable. Operation of lateral growth and thickness growth can well explain the influence of pressure on the structure, stability and the disorder to order transformation.

Keywords: Polylactide, crystal structure, melting behavior, recrystallization, high pressure

\section{Introduction}

Poly(L-lactide) is a semicrystalline polymer well known as a medically and environmentally friendly material due to its non-toxicity, biodegradability and biocompatibility, and it is producible from the renewable sources. ${ }^{1-6}$ It has been intensively studied with regards to the relationships between microstructure and macroscopic properties, which are related to its crystallization history and crystalline structure. However, the crystallization behavior and crystalline structure are still not fully well-understood, ${ }^{7}$ especially, the crystallization of PLLA under pressure has been seldom reported.

Crystallization behaviors including role of mobile phases, lamellar growth, phase transformation, morphology, nucleation and growth of nuclei, orientation and stack of lamellae, and chain fold modes under high pressure are peculiar. ${ }^{8-18}$ The crystallization of linear polyethylene under elevated pressure has been 
reported. Linear polyethylene crystallized under pressure may have a density approaching the theoretical crystal density and a melting point close to the limiting value for large, perfect crystals. It emerges that the polymer crystallizes under high pressure by coupling of two mechanisms: lamellar thickening growth and lateral growth. ${ }^{8}$ It is well known that under suitably high pressure the more usual chain-folded crystallization gives way to extended chain crystals for polyethylene. ${ }^{17}$ Crystal modification was still observed in high pressure crystallization of random propylene-ethylene copolymers, and more stable crystal structures were formed under high pressure. ${ }^{18}$

In this paper, we report the influence of pressure on crystalline structure of PLLA. The structure stabilization, reformation, recrystallization and melting behaviors are investigated employing time-resolved SR-SAXS and DSC.

\section{Experimental Part}

\section{Materials}

PLLA sample was purchased from Sigma-Aldrich. The average molecular weight 34100 and polydispersity index 1.39 were determined by gel permeation chromatograph (GPC, Waters 410) against mono-dispersed polystyrene standards.

\section{Sample Preparation and PVT Equipment}

Samples of PLLA melt-crystallized under high pressure $\left(\mathrm{P}_{\mathrm{c}}\right)$ were prepared using PVT100 equipment (SWO Polymertechnik GmbH). Approximately $50 \mathrm{mg}$ of PLLA was placed between two linear calibrated Teflon stoppers in the thermo cell of PVT100 equipment, and heated to $220^{\circ} \mathrm{C}$ for $1 \mathrm{~min}$, then quenched to the temperature $\left(\mathrm{T}_{\mathrm{c}}\right)$ as soon as possible for isothermal crystallization. Pressure $\left(\mathrm{P}_{\mathrm{c}}\right)$ was loaded at $\sim 180^{\circ} \mathrm{C}$ during the cooling process. The samples were kept at the isothermal crystallization temperature under the pressure for adequate time. After the isothermal crystallization, the samples were cooled to the room temperature rapidly for further investigation.

\section{Wide-Angle X-ray Diffraction Measurement}

WAXD investigations of the samples prepared at various pressure were performed on a Rigaku PC X-ray scattering (Rigaku Co., D/max 2500V) with Ni-filtered $\mathrm{CuK}_{\alpha}$ radiation $(\lambda=0.1542 \mathrm{~nm})$ at room temperature. All the measurements were operated at $50 \mathrm{kV}$ and $250 \mathrm{~mA}$ from $10^{\circ}$ to $35^{\circ}$ at a $2 \theta$ scan rate of $3^{\circ} / \mathrm{min}$.

The crystallite size was estimated on the basis of Scherrer's equation: 


$$
D=\frac{k \lambda}{\beta \cos \theta}
$$

Where $k=0.90, \beta$ is half-width at high maximum of diffraction peak, $2 \theta$ is Bragg diffraction angle.

\section{Differential Scanning Calorimetry}

A Perkin-Elmer DSC-7 differential scanning calorimeter was employed. The samples were encapsulated in aluminum pans. The calibration was performed with indium and all tests were run employing ultra pure nitrogen as purge gas. The measurements were performed during heating with rate $10^{\circ} \mathrm{C} / \mathrm{min}$. The melting points were obtained from the heating process.

\section{Synchrotron Small-Angle X-Ray Scattering}

The SAXS experiments were performed using synchrotron radiation with $\lambda$ $=0.150 \mathrm{~nm}$ at Beamline A2 of HASYLAB (Hamburg, Germany) and synchrotron radiation with $\lambda=0.154 \mathrm{~nm}$ at Beamline $1 \mathrm{~W} 2 \mathrm{~A}$ of Beijing Synchrotron Radiation Facility (Beijing, China). All of the data was corrected for background scattering before analysis and treated with software Fit 2D.

\section{Time-Resolved Synchrotron Small-Angle X-Ray Scattering}

The samples prepared were wrapped in ultra-thin aluminum foil, placed in SRSAXS equipment with a heater and a thermal control system. Scanning the sample during the heating process was performed at $3^{\circ} \mathrm{C} / \mathrm{min}$ from $150^{\circ} \mathrm{C}$ until it completely melted at $200{ }^{\circ} \mathrm{C}$, the exposure time was 30 s.

\section{Results and Discussion}

The WAXD profiles of PLLA isothermally crystallized at $135^{\circ} \mathrm{C}$ under various crystallization pressures $\left(\mathrm{P}_{\mathrm{c}}\right)$ are shown in Figure 1. As seen in the diffractograms, the relative intensities of the diffraction peaks are not necessarily the same among the samples crystallized at the various $\mathrm{P}_{\mathrm{c}}$, probably due to the preferential orientation of the crystallites which depends on the crystallization history. Two strong diffractions $(200) /(110)$ and (203) can be obviously observed for all the samples, while some other diffractions including (103), (010) and (210) are quite weak in samples prepared under $1 \mathrm{k}$ bar and above, which is ascribed to the low averaged crystallization rate under pressure. The peaks of (200)/(110) and (203) diffraction shifted to smaller $2 \theta$ with pressure increasing. The changes among the WAXD profiles indicating the growth rate, the crystal structure and the crystallite size are $\mathrm{P}_{c}$ dependent. 


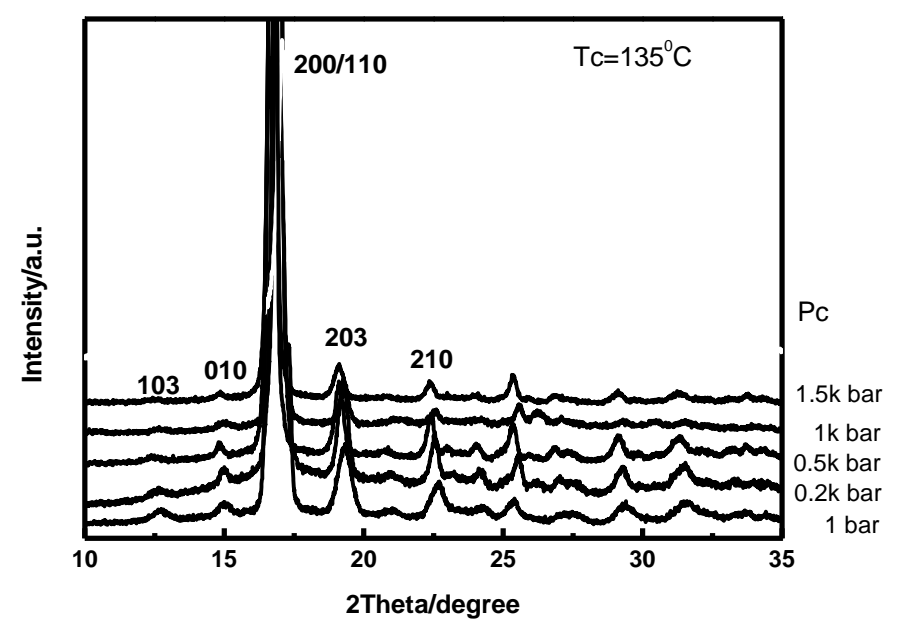

Figure 1 Film diffraction profiles measured at room temperature for PLLA samples melted-crystallized at $135^{\circ} \mathrm{C}$ at various pressures.

The half-width of the diffraction peaks at high maximum also changes with $\mathrm{P}_{\mathrm{c}}$. Figure 2 reveals the $P_{c}$ dependence of inverse lattice spacing and crystallite size estimated for the (203) diffraction. The inverse lattice spacing $\left(\mathrm{d}^{-1}{ }_{203}\right)$ becomes smaller, therefore the lamellar stacking becomes looser gradually with $\mathrm{P}_{\mathrm{c}}$ increasing. We considered that it would be attributed to the lamellar sliding in the direction perpendicular to the axe of $\mathrm{P}_{\mathrm{c}}$. The half-width at high maximum of the diffraction peak becomes wider with $\mathrm{P}_{\mathrm{c}}$ increasing, corresponding to the decrease in the crystallite size $\left(D_{203}\right)$. There is a large decrease for the values of $d_{203}{ }^{-1}$ and $\mathrm{D}_{203}$ of samples prepared under $1 \mathrm{k}$ bar. According to the X-ray diffraction result, we speculate that a disordered $\alpha$ form of PLLA is formed at $1 \mathrm{k}$ bar and above. It is known that the disordered $\alpha$ form (named $\alpha^{\prime}$-form) of PLLA can be formed at crystallization temperature below $120^{\circ} \mathrm{C}$ at atmospheric pressure. ${ }^{19,20}$ The chain folded mode and lamellar orientation of PLLA are probably not only $\mathrm{T}_{\mathrm{c}}$ dependent but also $\mathrm{P}_{\mathrm{c}}$ dependent. The pressure dependence of the equilibrium melting point can be calculated through the application of the Clapeyron equation that defines the equilibrium between two phases. ${ }^{18}$ Consequently, the under-cooling $\left(\Delta \mathrm{T}=\mathrm{T}_{\mathrm{m}}{ }^{0}\right.$ $\mathrm{T}_{\mathrm{c}}$ ) increases with $\mathrm{P}_{\mathrm{c}}$. As already discussed in the papers, the $\alpha^{\prime}$ form of PLLA takes a disorder structure concerning the conformation and stacking modes of the chains. ${ }^{19,}{ }^{20}$ It can be explained by the increase of the under-cooling and the peculiar crystallization behavior under pressure, and this will be further explained 
in the follow part. The remarkable intensity decrease and flatten of diffraction peaks in WAXD profiles indicate a continuous and gradual weakening of structural regularity, the degree of ordering is far lower than that of $\alpha$ form.

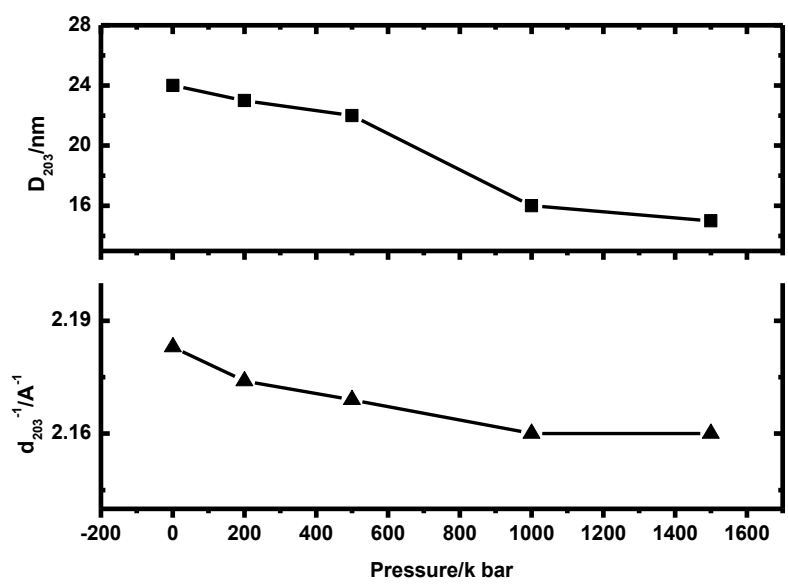

Figure 2 Changes of the crystal size $\left(\mathrm{D}_{203}\right)$ and inverse lattice spacing for (203) diffractions $\left(\mathrm{d}^{-1}{ }_{203}\right)$ as a function of crystallization pressure at $135^{\circ} \mathrm{C}$.

In order to get more information about the crystalline structure under pressure, we employed SAXS data to calculate the structure parameters including the long period $(L)$, the crystal thickness $\left(d_{c}\right)$ and the non-crystalline layer thickness $\left(d_{a}\right)$. Figure 3 (a) shows the typical SAXS profile of PLLA samples crystallized under high pressure. One scattering peak is observed, indicating the stacking structure is lamellar. The value of $\mathrm{q}$ for the scattering peak is about $0.3 \mathrm{~nm}^{-1}$. Figure 3(b) presents the method how to calculate the structural parameters.

One dimensional electron density correlation function is used to analyze the SAXS result of PLLA samples. ${ }^{21}$ For PLLA samples crystallized under pressure, a layer named the transition phase located intermediate between crystalline and amorphous layer can be found. The structural parameters including the long period, crystal thickness, thickness of non-crystalline phase, and thickness of transition layer $\left(\mathrm{d}_{\mathrm{tr}}\right)$ (that is interphase) are obtained. Furthermore, the relationship among the parameters is $\mathrm{L}=\mathrm{d}_{\mathrm{c}}+\mathrm{d}_{\mathrm{a}}+2 \mathrm{~d}_{\mathrm{tr}}$. 

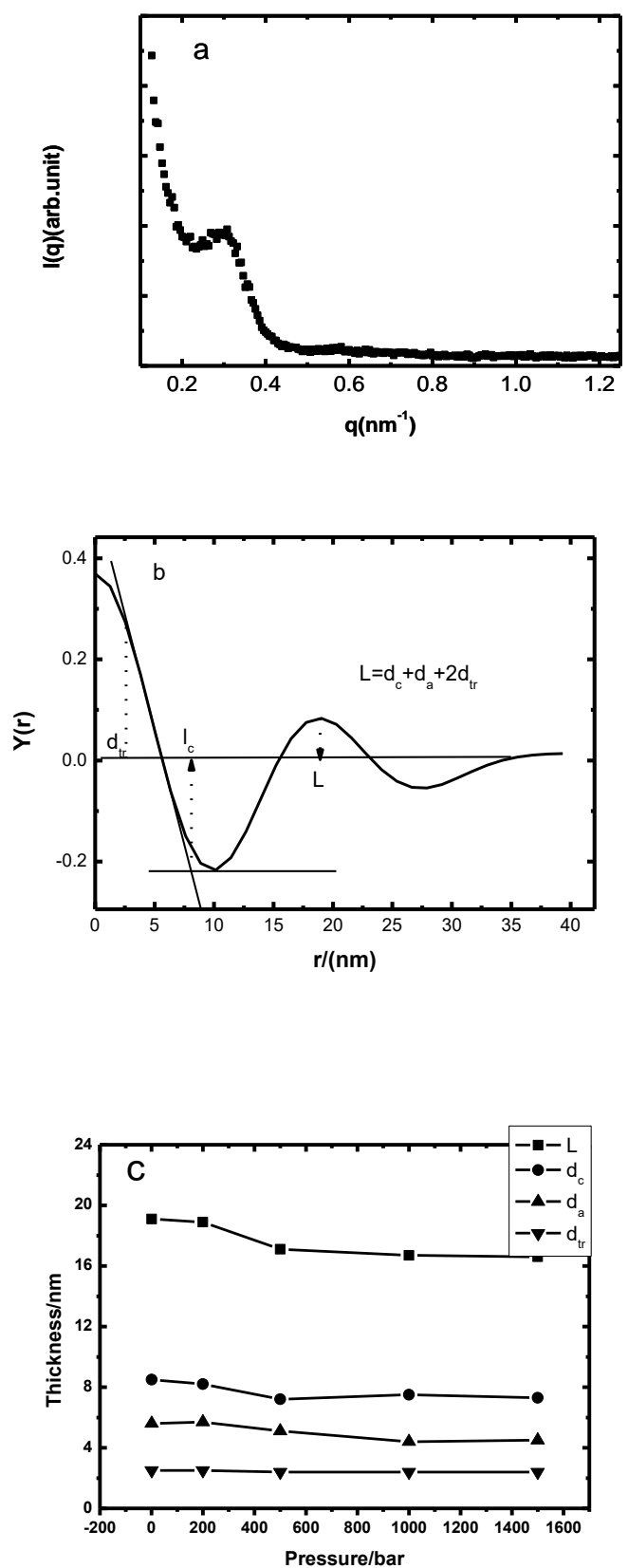

Figure 3 (a) Typical SAXS pattern of PLLA crystallized at $135^{\circ} \mathrm{C}$ under high pressure; (b) Structure analysis using 1D electron density correlation function: three phases including crystalline phase, amorphous phase and interphase; (c) Phase structure calculated from SAXS: its Long period $(L)$, crystal thickness $\left(d_{c}\right)$, amorphous thickness $\left(\mathrm{d}_{\mathrm{a}}\right)$ and transition layer thickness $\left(\mathrm{d}_{\mathrm{tr}}\right)$ as a function of $\mathrm{P}_{\mathrm{c}}$.

The structural parameters as a function of $\mathrm{P}_{c}$ are shown in Figure 3(c). The values of $L, d_{c}$ and $d_{a}$ decrease with $P_{c}$. The crystallinity of the samples is larger than $50 \%$, and then the values of $d_{c}$ are larger than $d_{a}$ shown in Figure 3 (c). ${ }^{22-24} \mathrm{~A}$ remarkable decrease can be found for the values of the samples prepared under 1 $\mathrm{k}$ bar compared with those made under lower pressure. As discussed above, there 
exists an obvious change in the WAXD profile under $1 \mathrm{k}$ bar as shown in Figure 1, and a large decrease for inverse spacing and crystallite size for sample prepared under $1 \mathrm{k}$ bar as shown in Figure 2. The values of transition layer thickness are nearly invariable, while the fraction of this layer becomes larger with $\mathrm{P}_{\mathrm{c}}$ because of the decrease of long period.

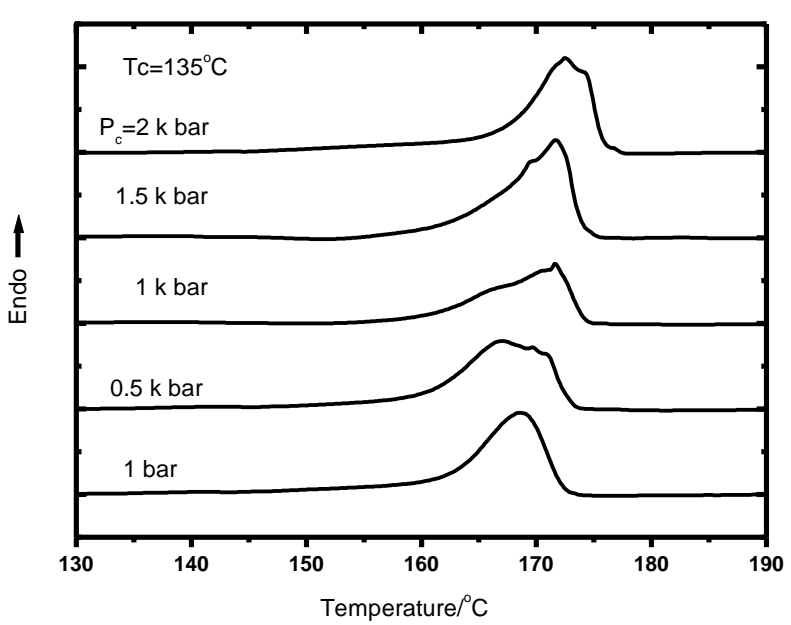

Figure 4 Effect of crystallization pressure on melting behavior of PLLA samples crystallized at $135^{\circ} \mathrm{C}$.

A relatively larger decrease can be found for the values of $\mathrm{d}^{-1}{ }_{203}$, which was calculated according to WAXD data. The values, $L, d_{a}, d_{c}$ obtained from SAXS for the sample crystallized at $135^{\circ} \mathrm{C}$ at $1 \mathrm{k}$ bar, keep nearly invariable at $\mathrm{P}_{\mathrm{c}}$ above 1 $\mathrm{k}$ bar. The result indicates the $\mathrm{P}_{\mathrm{c}}=1 \mathrm{k}$ bar is probably the boundary pressure for PLLA samples crystallized at $135^{\circ} \mathrm{C}$, which divides the pressure into the high and low pressure region, the crystalline structure and the crystallization behaviors are probably distinguished. Only ordered crystalline phase ( $\alpha$ phase) is formed for samples crystallized under pressures below $1 \mathrm{k}$ bar, and $\alpha$ phase and the disordered $\alpha$ phase ( $\alpha^{\prime}$ phase) coexist for samples crystallized under $1 \mathrm{k}$ bar and above. As mentioned above, the under-cooling increases under high pressure. The diffusion of chain segment is confined by the action of high pressure. Meanwhile, chain folded mode and lamellae sliding make the degree of order and orientation decrease, as a consequence, disordered $\alpha$ form is formed.

It was reported that polymers crystallized under pressure may have a melting point close to the limiting value for large and perfect crystals. In present work, 
the values of the crystallite size, the long period, crystalline thickness and the degree of order decrease with pressure for the PLLA prepared, and the decrease of the structural parameters can be explained by the low growth rate and the confined crystallization behavior under high pressure. In order to get more information about the crystalline structure formed under pressure, the melting behaviors of the samples were studied by differential scanning calorimetry (DSC). The melting behavior and the melting points were obtained from the first heating at the rate of $2^{\circ} \mathrm{C} / \mathrm{min}$. Multiple melting behaviors were observed in samples prepared under pressure as illustrated in Figure 4. A small melting peak around $165^{\circ} \mathrm{C}$ just prior to the melting point was observed, which corresponds to the disordered $\alpha$ phase. $^{20}$

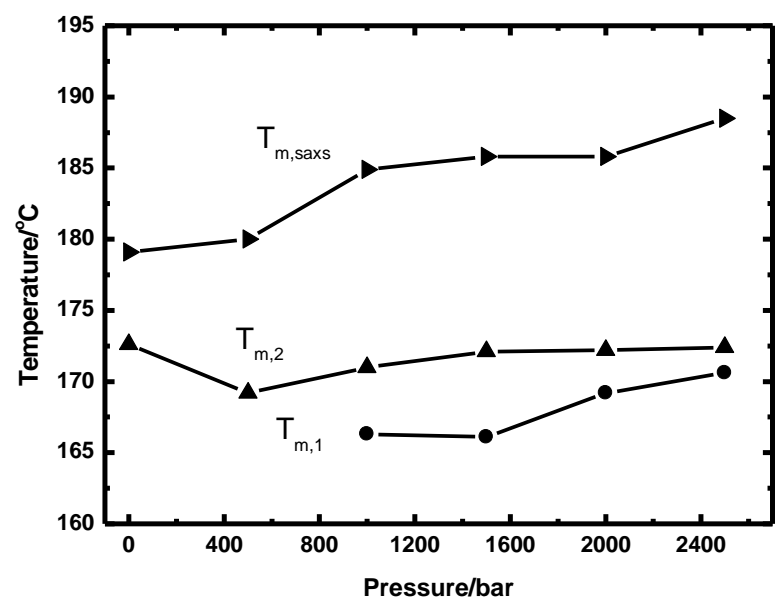

Figure 5 The melting points of PLLA samples isothermally crystallized at $135^{\circ} \mathrm{C}$ at various pressures, $\mathrm{T}_{\mathrm{m}, 1}$ and $\mathrm{T}_{\mathrm{m}, 2}$ were determined by DSC performed at $10^{\circ} \mathrm{C}$, and $\mathrm{T}_{\mathrm{m} \text {, saxs }}$ was determined by SAXS.

Figure 5 pronounces the melting points $\left(\mathrm{T}_{\mathrm{m}, 1}, \mathrm{~T}_{\mathrm{m}, 2}\right)$ determined by DSC, and the complete melting points determined by SAXS ( $\mathrm{T}_{\mathrm{m}}$, SAXS) as a function of pressure. The $\mathrm{T}_{\mathrm{m}}$, SAXS is the complete melting point for the crystalline structure after reformation and recrystallization during the heating. There is only one melting point $\left(\mathrm{T}_{\mathrm{m}, 2}\right)$ decreasing with pressure in the low pressure region is found, while in the high pressure region, there exist two melting points, $T_{m, 1}$ and $T_{m, 2}$, and they increase with pressure. As we all know that only ordered $\alpha$ phase is formed for PLLA crystallized $135^{\circ} \mathrm{C}$ at atmospheric pressure. ${ }^{20,25,26}$ In the low 
pressure region, the crystallization behaviors of PLLA were influenced by the action of pressure, but the pressure might be not strong enough to affect the chain fold and sliding, it only influenced the crystallization growth rate and crystal stacking. The crystallization growth rate decreased and the stacking became loose, but only ordered $\alpha$-form crystal was formed. Consequently, there was only one melting point, and it decreased with pressure. In high pressure region, the disordered $\alpha$ form crystalle structure was observed because of the influence of pressure, so two melting points were revealed. The increase of the melting points with pressure may be explained by the peculiar lamellae thickening mechanism. ${ }^{17}$

The lateral growth is the most common way which forms chain folded lamellae for polymer crystallization, while the growth into the thickness direction which may form extended chain lamellae may occur in polymer crystallization process under certain high pressures. They named the new growth mechanism as thickness growth, and the growth mechanism is by sliding diffusion with chain sliding. The two distinct crystallization mechanisms are operative simultaneously in the crystallization process of PLLA under the high pressure region, more perfect ordered $\alpha$ phase was formed by the lateral growth and thickness growth, and disordered $\alpha$ phase was formed because of chain sliding. Moreover, the thickness growth made crystal lamellae thicker. They would explain why there were two melting points and they increased with pressure. The values of $T_{m}$, SAXs are relatively much higher than $T_{m, 1}$ and $T_{m, 2}$, which confirm the formation of a new more stable structure during the heating, certainly it still indicates the occurrence of reformation and recrystallization as temperature jump. The values of $\mathrm{T}_{\mathrm{m}}$, SAXs approach the values of the equilibrium melting point $\left(\mathrm{T}_{\mathrm{m}}{ }^{0}\right)$, but much smaller than $\mathrm{T}_{\mathrm{m}}{ }^{0}$ indicating the new more stable structures are not extended chain crystal. The increase of $\mathrm{T}_{\mathrm{m}}$, SAXs with pressure can be explained by Clapeyron equation.

We also investigated the stabilization, reformation, disorder to order transformation and recrystallization of samples prepared employing timeresolved synchrotron SAXS as shown in Figure 6. PLLA samples crystallized at $135^{\circ} \mathrm{C}$ under 1 bar Figure 6 (a) and $1 \mathrm{k}$ bar Figure (b), then heated in stepwise manner in time-resolved SR-SAXS, with steps of $3^{\circ} \mathrm{C} / \mathrm{min}$. the correlation function at the beginning is identical with that obtained at the end of the 
isothermal crystallization at $135^{\circ} \mathrm{C}$. No changes occur up to $145.5^{\circ} \mathrm{C}$, i.e., the initial structure remains stable over $10.5^{\circ} \mathrm{C}$. Then reformation and recrystallization processes set in. Each one of the subsequent temperature steps leads to an increase of the long period and the crystal thickness. Stabilization for the previous structure, reformation and recrystallization takes place after a temperature jump in the melting range, which changes the stack structure, and a new more stable crystalline structure was formed. ${ }^{20,25}$ For the samples prepared under $1 \mathrm{k}$ bar and above, phase transformation from disordered $\alpha$ form to the ordered $\alpha$ form occurs in the temperature range from about $160{ }^{\circ} \mathrm{C}$ to $171.4{ }^{\circ} \mathrm{C}$.
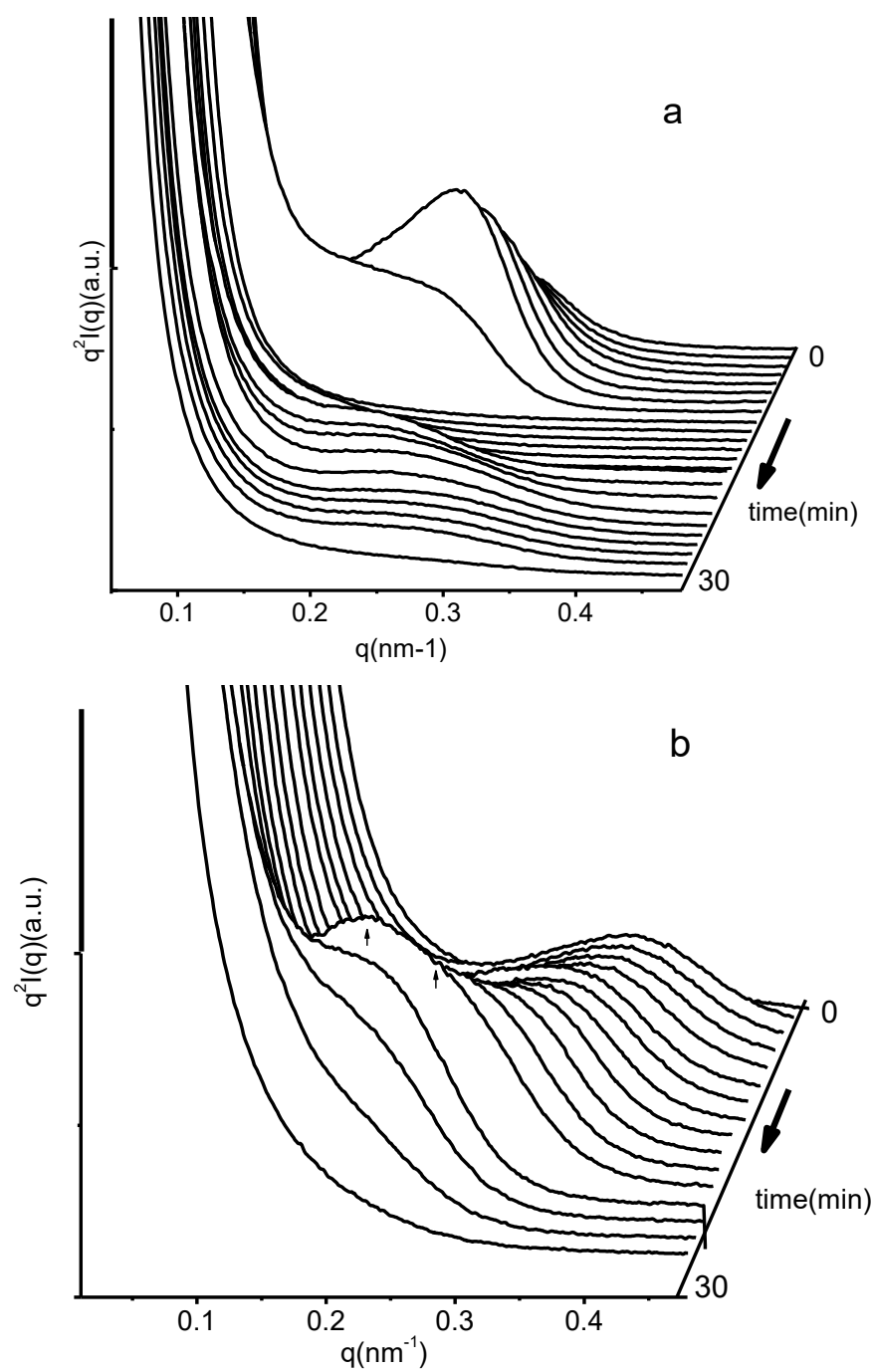

Figure 6 Time-resolved SR SAXS: Melting and recrystallization process of samples prepared at $135^{\circ} \mathrm{C}$ under (a) 1 bar and (b) $1 \mathrm{k}$ bar.

We found the scattering intensity of sample prepared at $\mathrm{P}_{c}=1$ bar shown in Figure 6 (a) is stronger than those for the sample prepared at $P_{c}=1 \mathrm{k}$ bar shown in Figure 6 (b), indicating the degree of order is better for the sample prepared at 
atmospheric pressure. In Figure 6 (b), the SAXS peaks are relatively broad and flat. Meanwhile, the peak can be divided into two peaks as temperature jump. It has been confirmed that the disordered $\alpha$ form (that is $\alpha^{\prime}$ form) is formed under $\mathrm{P}_{\mathrm{c}}=1 \mathrm{k}$ bar and above by WAXD (and it can be still confirmed by DSC result in Figure 4), which suggests the phase transformation from disordered $\alpha$ form to the ordered $\alpha$ form. The transformation temperature range is from $160^{\circ} \mathrm{C}$ to $174.3^{\circ} \mathrm{C}$ as shown in Figure 6 (b).
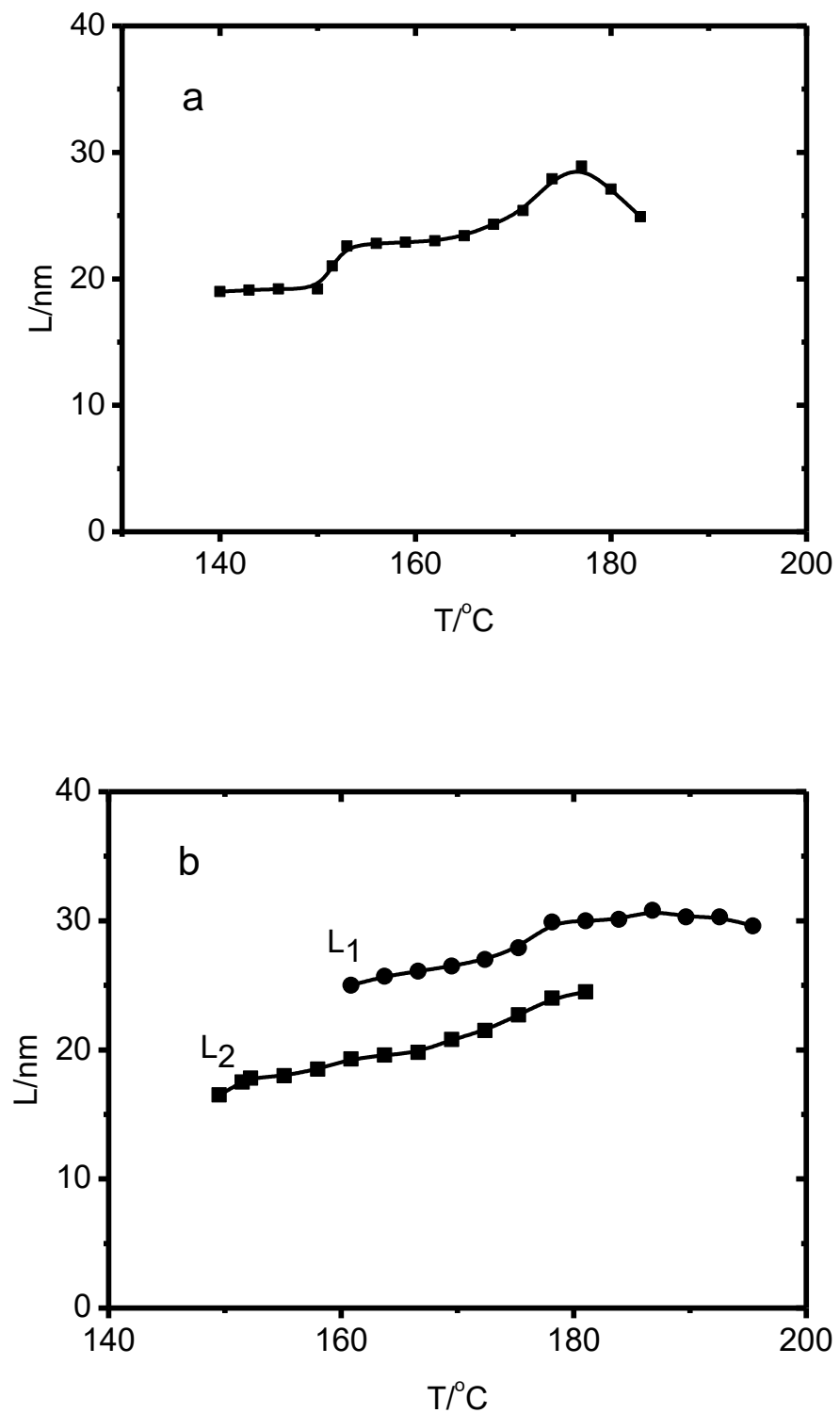

Figure 7 The long period (L) of samples prepared at $135^{\circ} \mathrm{C}$ under (a) 1 bar and (b) $1 \mathrm{k}$ bar as a function of temperature (T) during heating process. The long period, L1 and L2, calculated from the two SAXS peaks in one singular profile.

The long period (L) of the measured samples can be obtained from the SAXS 
profile showed in Figure 6. Figure 7 shows the evolution of the long period of PLLA prepared at $135{ }^{\circ} \mathrm{C}$ under 1 bar (a) and $1 \mathrm{k}$ bar (b) during heating. For PLLA sample crystallized at $135{ }^{\circ} \mathrm{C}$ under 1 bar, the values of the long period increased at the initial stage of heating as shown in Figure 7 (a), indicating that recrystallization and lamellae thickness occurred. Moreover, when the temperature was lower than $180{ }^{\circ} \mathrm{C}$, recrystallization growth rate was larger than that of melting, and then the value of the long period increased with temperature. When the temperature was above $180{ }^{\circ} \mathrm{C}$, the melting rate became faster than recrystallization growth rate, and the value of the long period decreased. The crystalline structure became more perfect after recrystallization, and the melting temperature increased up to $186{ }^{\circ} \mathrm{C}$ determined by SAXS, which was much higher than the melting point of the sample as shown in Figure 4 and Figure 5. The PLLA sample prepared at $135{ }^{\circ} \mathrm{C}$ under $1 \mathrm{k}$ bar was heated to $200{ }^{\circ} \mathrm{C}$, phase transformation took place except for recrystallization and melting as temperature jumping. Within the heating temperature range from $150{ }^{\circ} \mathrm{C}$ to $160{ }^{\circ} \mathrm{C}$, the value of the long period increased by recrystallization of $\alpha$ form and $\alpha^{\prime}$ form of PLLA crystals as shown in Figure 7 (b). In the second stage range from $160{ }^{\circ} \mathrm{C}$ to $180{ }^{\circ} \mathrm{C}$, the transformation of disordered $\alpha^{\prime}$ form to the ordered $\alpha$ form occurred, which was confirmed by WAXD and DSC as shown in Figure 1 and Figure 4. It is known that the stack packing of ordered $\alpha$ form is more compact than that of $\alpha^{\prime}$ form, therefore, the value of the long period decreases after phase transformation. As a result, the increase of the long period is attributed to recrystallization. Moreover, the SAXS profiles at high temperatures could be divided into two peaks as shown in Figure 6 (b), and the values of $\mathrm{q}$ is $\sim 0.35 \mathrm{~nm}^{-1}$ and $\sim 0.25$ $\mathrm{nm}^{-1}$. The values of the long period calculated according to $\mathrm{q} \sim 0.25 \mathrm{~nm}^{-1}$ is much large than that according to $\mathrm{q} \sim 0.35 \mathrm{~nm}^{-1}$, indicating a long rang ordered phase existed in PLLA sample prepared under high pressure. During heating, the ordered phase crystallized rapidly, and the long period was up to $30 \mathrm{~nm}$, which was $5 \mathrm{~nm} \sim 10 \mathrm{~nm}$ larger than $\mathrm{q} \sim 0.35 \mathrm{~nm}^{-1}$ at the same temperature. In the third stage above $180{ }^{\circ} \mathrm{C}$, the value of the long period nearly kept invariable, indicating the crystallization growth rate is equal to the melting rate. Finally, the crystalline structure was completely melted, when heated to $196{ }^{\circ} \mathrm{C}$, which was much higher 
than that of PLLA sample prepared at 1 bar. The melting temperature of the crystalline structure was much higher, which is equal to the equilibrium melting temperature. Consequently, the crystalline structure was not chain-folded crystal but chain-extended crystal. The long rang ordered phase is produced by the shear flow effect of high pressure during PLLA crystallization, and it was able to transformed into crystalline phase (chain-extended phase) quickly at high temperature.

\section{Conclusions}

The results show that the crystallite size and the lamellar stacking of PLLA samples crystallized under pressure are distinguished from those at atmospheric pressure. The lattice spacing increases indicating lamellar slides in the direction perpendicular to the pressure. The crystallite size decreases with $\mathrm{P}_{c}$, indicating the diffusion and growth are confined by pressure. The structural parameters, including long period $(L)$, crystal thickness $\left(d_{c}\right)$ and amorphous layer thickness $\left(d_{a}\right)$ decrease with $P_{c}$, but thickness of intermediate layer $\left(d_{t r}\right)$ is invariable. Multiple melting behaviors were observed for samples prepared under $1 \mathrm{k}$ bar and above, the results together with those of WAXD show the disordered $\alpha$-phase $\left(\alpha^{\prime}\right)$ is formed under such high pressures. However, the melting points (determined by DSC) of PLLA samples prepared increase with pressure, which shows that more thermal stable structure is formed under pressure, it is probably the thickening mechanism under pressure is not only lateral growth but also lamellar thickening growth. Meanwhile, the melting point for complete melt determined by timeresolved SAXS confirms the formation of a new stable phase via disorder to order transformation, reformation and recrystallization during heating. Chain-extended crystalline phase can be formed after recrystallization for PLLA prepared under high pressure.

During the follow heating, disorder to order transformation, reformation and recrystallization completely change the previous crystal structure and stacking, a new more stable crystal structure is formed after a temperature jump in the melting range. Disordered $\alpha\left(\alpha^{\prime}\right)$ crystal structure transformed to ordered $\alpha$ form was observed by time-resolved synchrotron SAXS.

\section{Acknowledgements}

This work is supported by the National Natural Science Foundation of China 
(20974077, 51073157, 51173130, 51103151, 21274149) Programs and subsidized by the Special Funds for National Basic Research Program of China (2010CB631102). We appreciated assistances provided by Prof. Zhonghua Wu, High Energy Accelerator Research Organization, CAS, and HASYLAB, Hamburg, Germany.

\section{References}

1. A. J. Nijenhuis, D. W. Grijpma, A. J. Pennings, Macromolecules 1992, 25, 6419-6424.

2. J. R. Drogan, Poly(L-lactic acid) Properties and Prospects of an Environmentally Benign Plastic: American Chemical Society: Washington DC, 1999, 145-149.

3. M. Fujita, Y. Doi, Biomacromolecules 2003, 4, 1301-1307.

4. R. C. Thomson, M. C Wake, M. J. Yaszemski, A. G. Mikos, Adv. Polym. Sci. 1995, 122, 245-274.

5. A. Sodegard, M Stolt, Prog. Polym. Sci. 2002, 27, 1123-1163.

6. H. D. Kim, E. H. Bae, I. C. Kwon, R. R. Pal, J. D Nam, D. S. Lee, Biomaterials 2004, 25, 2319-2329.

7. K. Takahiko, K. Toshiji, Crystallization of Poly(L-lactide acid) P-19 Polymer Crystallization, European Discussion Meeting on Polymer Physcis, Waldau Schwarzwald Germany 2005, 10, 05-08.

8. M. Hikosaka, Polymer 1987, 28, 1257-1264.

9. M. Hikosaka, Polymer 1990, 31, 458-468.

10. P. H. Geil, F. R. Anderson, B. Wunderlich, T. Arakawa, J. Polym. Sci. 1964, A2, 3707-3719.

11. B. Wunderlich, L. Melillo, Makromol. Chem. 1968, 118, 250.

12. D. C. Bassett, D. V. Rees, Nature 1972, 219, 368.

13. D. C. Bassett, Polymer 1976, 17,460-470.

14. D. C. Bassett, B. A. Khalifa, Polymer 1973, 14, 390-393.

15. D. C. Bassett, B. A. Khalifa, Polymer 1976, 17, 275-283.

16. D. C. Bassett, S. Block, G. J. Piermarini, J. Appl. Phys. 1974, 45, 4146-4150.

17. M. Hikosaka, S. Rastogi, A. Keller, H. Kawabata, J. Macromol. Sci. Phys. B31(1), 1992, 87-131.

18. Anita Dimeska, Paul J. Phillips, Polymer 2006, 47, 5445-5456.

19. J. M. Zhang, K. Tashiro, A. J. Domb, H. Tsuji, Macromol. Symp. 2006, 242, 
274-278.

20. J. M. Zhang, K. Tashiro, H. Tsuji, A. J. Domb, Macromolecules 2008, 41, 1352-1357.

21. G. R. Strobl, M. Schneider, J. Polym. Sci., Polym. Phys. Edition 1980, 18, 1343-1359.

22. Z. G. Wang, X. H. Wang, B. S. Hsiao, S. Andjelic, D. Jamiolkowski, J. McDivitt, J. Fischer, J. Zhou, C. C. Han, Polymer 2001, 42 (21), 8965-8973.

23. Z. G. Wang, B. S. Hsiao, X. H. Zong, F. Yeh, Z. J. Zhou, E. Dormier, D. D. Jamiolkowski, Polymer 2000, 41 (2), 621-628.

24. X. H. Zong, Z. G. Wang, B. S. Hsiao, B. Chu, J. J. Zhou, D. D. Jamiolkowski, E. Muse, E. Dormier, Macromolecules 1999, 32 (24), 8107-8114.

25. Tai-Yon Cho, G. Strobl, Polymer 2006, 47, 1036-1043.

26. J. M. Zhang, Y. X. Duan, H. Sato, H. Tsuji, I. Noda, S. Yan, Y. Ozaki, Macromolecules 2005, 38, 8012-8021. 